\title{
AVALIAÇÃO HISTOLÓGICA DO PROCESSO DE REPARAÇÃO DA SUPERFÍCIE ARTICULAR DE COELHOS ${ }^{1}$
}

\author{
HISTOLOGIC EVALUATION OF THE REPAIR PROCESS \\ IN THE ARTICULAR SURFACE OF RABBITS
}

\section{Tayse Domingues de Souza ${ }^{2}$ Ricardo Junqueira Del Carlo ${ }^{3}$ Marlene Isabel Vargas Viloria $^{4}$}

\section{RESUMO}

O processo de reparação da superfície articular foi avaliado microscopicamente em uma falha osteocondral produzida no sulco troclear esquerdo de 12 coelhos adultos. Observou-se preenchimento inicial com tecido de granulação, com diferenciação tecidual em cartilagem hialina e reposição parcial do osso subcondral excisado sete semanas após a cirurgia. Houve formacão de fendas entre o tecido de reparação e o tecido ósseo adjacente, sempre em áreas onde não ocorreu remodelação óssea. Nos animais em que o fundo e as laterais da falha osteocondral eram constituídos por osso subcondral compacto, contendo poucos vasos sangüíneos, não foi observada remodelação óssea e o tecido de reparação que preenchia a falha não foi integrado ao tecido ósseo adjacente. Os resultados evidenciam a importância da remoção completa do osso subcondral compacto nos procedimentos cirúrgicos em superfícies articulares, possibilitando melhor afluxo sangüíneo a partir do osso esponjoso subjacente e, conseqüentemente, melhor remodelação óssea e integração do tecido de reparação ao fundo da falha.

Palavras-chave: cartilagem, osteocondral, articulações.

\section{SUMMARY}

The repairing process in the articular surface was evaluated microscopically in an osteochondral gap produced in the left troclear groove of 12 adult rabbits. It was observed that the granulation tissue wich initially filled this gap had diferentiated into hyaline cartilage by 4 weeks after surgery, presenting parcial reconstitution of subchondral bone excised at seven weeks following surgery. In some animals, cleft formation was observed between the repair tissue and adjacent bone, always where bone remodeling did not occured. In animals wich the bottom and lateral edges of the defect were formed by lamelar subchondral bone with few blood vessels, bone remodeling was

\begin{abstract}
not observed, having no attachment of the repair tissue to the adjacent bone. The results show the importance of complete removal of the lamelar subcondral bone during the surgical procedures in the articular surface, in order to allow better blood supply from the subjacent cancellous bone, better bone remodeling, and attachment of the repair tissue to the bottom of the defect.
\end{abstract}

Key words: cartilage, osteocondral, joints.

\section{INTRODUÇÃO}

As lesões superficiais da cartilagem articular, que não envolvem o osso subcondral, possuem pouca capacidade de reparação, por se tratar de tecido desprovido de irrigação sangüínea e dependente da vascularização proveniente da medula óssea para que ocorra migração de células mesenquimais, responsáveis pelo processo de cicatrização (MITCHELL \& SHEPARD, 1976; HURTIG $\boldsymbol{e}$ t al., 1988; FRENCH et al., 1989; SHAMIS et al., 1989; KIM et al., 1991; HANIE et al., 1992; SHAPIRO et al., 1993).

Nas falhas em que permanece a camada mais profunda da cartilagem articular, isto é, a zona de cartilagem calcificada, não há reparação a partir do osso subcondral (SHAMIS et al., 1989; KIM $\boldsymbol{e}$ t al., 1991; HANIE et al., 1992). Por outro lado, lesões que penetram o osso são reparadas com tecido fibroso, fibrocartilaginoso ou cartilaginoso seme-

\footnotetext{
${ }^{1}$ Apoio financeiro da FAPEMIG

${ }^{2}$ Médico Veterinário, Mestre, Departamento de Veterinária (DVT), Universidade Federal de Viçosa (UFV).

${ }^{3}$ Médico Veterinário, pesquisador CNPq, Professor Titular, DVT, UFV, 36571-000, Viçosa, MG. E-mail: ricarlo@mail.ufv.br. Autor para correspondência.

${ }^{4}$ Médico Veterinário, Professor Adjunto, DVT, UFV. 
lhante ao hialino (MITCHELL \& SHEPARD, 1976; RUDD et al., 1987; HURTIG et al., 1988; FRENCH et al., 1989; SHAMIS et al., 1989; KIM et al., 1991; HANIE et al., 1992; SHAPIRO et al., 1993).

SHAPIRO et al. (1993) descreveram a sequiência do processo de reparação de falhas osteocondrais na superfície articular de coelhos, em defeitos que se estendiam até o osso esponjoso. Inicialmente, o coágulo sanguíneo foi substituído por uma rede de fibrina, com proliferação de capilares a partir da medula óssea adjacente. Células mesenquimais invadiram a periferia do coágulo, distribuindo-se por todo o tecido de reparação. Superficialmente, ocorreu a formação de uma camada fibrosa, com fibras colágenas orientadas paralelamente à superfície articular. Mais profundamente, as células mesenquimais se diferenciaram em condroblastos. À medida que se processou a diferenciação celular, o tecido de reparação apresentou aspecto semelhante à cartilagem hialina. Na região mais profunda da cartilagem de reparação, observou-se um processo de ossificação endocondral e formação intramembranosa de osteóide, responsáveis pela reposição do osso subcondral. A reorganização da junção osteocondral e do osso subcondral como osso lamelar foi verificada 24 semanas após a cirurgia. Contudo, o tecido de reparação, até mesmo quando histologicamente semelhante à cartilagem hialina, difere da cartilagem articular normal, bioquímica e biomecanicamente.

SHAPIRO et al. (1993) sugeriram que a manutenção da integridade da cartilagem articular de reparação depende da reconstituição do tecido ósseo excisado. Somente em um pequeno número de animais, em que o osso subcondral havia sido reconstituído, a cartilagem de reparação não apresentava as alterações degenerativas observadas na maioria das falhas com 24 semanas de pós-operatório.

RADIN \& ROSE (1986) revisaram a função do osso subcondral na iniciação e progressão de lesões da cartilagem articular, sugerindo que alterações na sua arquitetura e densidade podem ter efeito significativo nos danos à cartilagem. Segundo eles, quando a rigidez da placa óssea subcondral é irregular e a superfície articular é submetida a uma carga, as regiões menos rígidas cedem mais do que o restante do osso. Na periferia da área menos rígida, a cartilagem sofre estiramento e pode se romper, havendo formação de fibrilações ou fendas verticais nesses locais.

A integração do tecido de reparação à falha pode estar relacionada com a sua profundidade e, por conseguinte, com o tipo de tecido exposto e a integração ao osso subcondral, o que não ocorria quando o fundo da falha era constituído por cartilagem calcificada (HURTIG et al., 1988; FRENCH et al., 1989; SHAMIS et al., 1989). Segundo HANIE $\boldsymbol{e t}$ al. (1992), uma vez excisada toda a zona de cartilagem calcificada e havendo vascularização disponível, a integração com a base do defeito não é significativamente melhorada com o aprofundamento da lesão.

Já a integração entre o tecido de reparação e a cartilagem articular da borda da lesão, provavelmente, está relacionada com a maneira pela qual são incisadas as margens da falha, observando-se melhor continuidade em margens incisadas perpendicularmente à superfície articular. Quando as margens eram oblíquas, a zona de cartilagem calcificada geralmente estava presente, prejudicando a integração (FRENCH et al., 1989).

SHAPIRO et al. (1993) observaram que em alguns cortes histológicos o tecido de reparação estava separado da cartilagem remanescente e do osso adjacente por uma fenda, na segunda semana de pós-operatório. Após quatro semanas, havia geralmente boa integração entre o tecido de reparação e a cartilagem remanescente na borda da falha. Porém, em alguns casos, havia ainda uma estreita separação entre esses tecidos, que pode influenciar a sobrevida da cartilagem de reparação.

\section{MATERIAL E MÉTODOS}

Foram utilizados 12 coelhos machos e fêmeas, da raça Nova Zelândia branco, com peso médio de $3,5 \mathrm{~kg}$ e idade entre sete e dez meses. Os animais foram mantidos em gaiolas individuais, alimentados com ração balanceada ${ }^{1}$ e água ad libitum. Para possibilitar a avaliação microscópica em diferentes fases do processo de reparação, foram criados três grupos experimentais de quatro animais, sacrificados em diferentes períodos pós-operatórios (GI, duas semanas de período pós-operatório; GII, quatro semanas de período pós-operatório e GIII, sete semanas de período pós-operatório).

Todos os animais receberam $40.000 \mathrm{UI} / \mathrm{kg}$ de peso corpóreo (pc) de penicilina procaína ${ }^{2}$ por via intramuscular (IM), duas horas antes da cirurgia. Foram administradas $40.000 \mathrm{UI} / \mathrm{kg} / \mathrm{pc}$ de penicilina benzatina $^{3}$ por via subcutânea, no pós-operatório imediato. A sedação do animais foi obtida com cloridrato de levomepromazina ${ }^{4}(2,0 \mathrm{mg} / \mathrm{kg} / \mathrm{pc}, \mathrm{IM})$ e a anestesia geral com a associação tiletaminazolazepam $^{5}(8,0 \mathrm{mg} / \mathrm{kg} / \mathrm{pc}$, via intravenosa). A articulação fêmuro-tíbio-patelar foi acessada através de uma incisão parapatelar lateral na cápsula articular, que permitiu a luxação medial da patela e a criação de uma falha retangular na cartilagem articular e osso subcondral do sulco troclear, com 2,0 $\mathrm{mm}$ de largura, 4,0 $\mathrm{mm}$ de comprimento e $1,5 \mathrm{~mm}$ de pro- 
fundidade. A articulação foi irrigada com solução fisiológica, a patela reposicionada e a cápsula articular e pele foram suturadas.

Após o sacrifício dos animais, foi obtido um fragmento contendo a região da falha osteocondral, que foi pré-fixado em líquido de Bouin por 6 horas e recortado transversalmente, obtendo-se assim dois fragmentos da falha de cada animal, que permaneceram no líquido de Bouin por mais 18 horas. Esses fragmentos foram descalcificados (LUNA, 1968), desidratados, incluídos em parafina, seccionados a $5 \mu \mathrm{m}$ de espessura, corados por Hematoxilina \& Eosina (GRIMALDI FILHO, 1981) e analisados ao microscópio óptico.

\section{RESULTADOS}

Em GI, o tecido observado preenchendo a falha osteocondral tinha aspecto de tecido de granulação, constituído por uma rede de colágeno infiltrada por células mesenquimais, permeado por vasos sangüíneos no fundo da falha. Foram observados focos de tecido cartilaginoso, geralmente na periferia, com matriz extracelular basófila e condrócitos no interior de lacunas, que se apresentavam hipertrofiados nas proximidades de vasos sangüíneos.

Foram visualizados osteoclastos reabsorvendo o osso trabecular necrótico adjacente à linha de fratura osteocondral, que ainda estava evidente em vários pontos. No fundo da falha, observou-se osteóide oriundo de formação intramembranosa e de ossificação endocondral. Nas áreas sem reabsorção óssea na linha de fratura, havia uma fenda entre o tecido de reparação e o tecido ósseo adjacente.

Em um animal, o fundo e as laterais da falha osteocondral constituíam-se de osso compacto com poucos vasos sangüíneos, sem túneis vasculares comunicando-se com a falha, e o tecido de reparação encontrava-se apenas sobreposto ao osso adjacente (Figura 1). A reabsorção óssea das bordas da falha estava restrita a poucas áreas onde havia vasos sangüíneos, ocorrendo integração do tecido de reparação com o osso subcondral nestes pontos.

A cartilagem articular remanescente na borda da falha apresentava diminuição da celularidade nas áreas adjacentes à linha de fratura osteocondral, observando-se com freqüência núcleos condrocíticos picnóticos e lacunas completamente vazias, indicativos de necrose tecidual. Houve perda da organização colunar dos condrócitos na zona radial, formação de ninhos celulares ou clones condroblásticos e encurvamento das colunas de células em direção à falha. Não havia integração entre o tecido de reparação e a cartilagem remanescente na borda da falha.

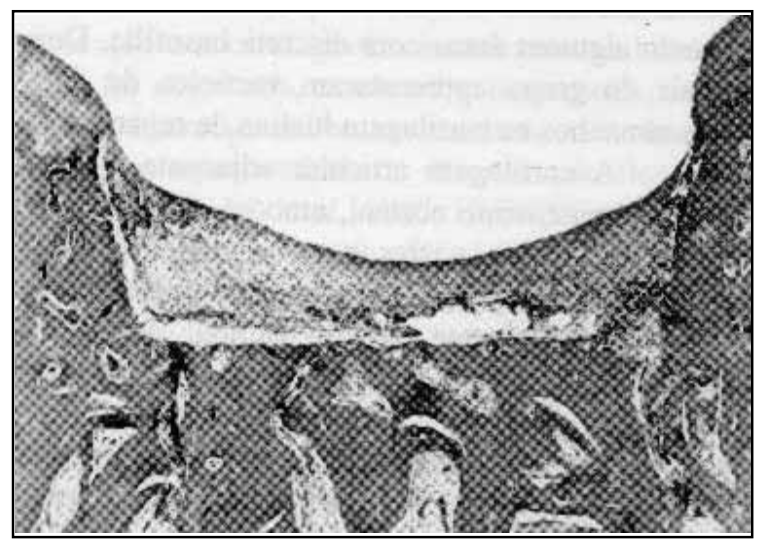

Figura 1 - Animal do GI que apresentou o fundo e as laterais da falha constituídos por osso subcondral compacto com poucos vasos sangüineos (1). Notar a linha de fratura intacta e a descontinuidade entre o tecido de reparação e o tecido ósseo adjacente (setas). H \& E. 70X.

Em GII, o tecido de reparação tinha aspecto de cartilagem hialina e, junto às laterais e ao fundo das falhas, verificou-se a presença de osso novo trabecular, formado nas áreas providas de vascularização e, predominantemente, a partir de ossificação endocondral (Figura 2). Em dois dos quatro animais deste grupo, verificou-se que as laterais e o fundo da falha eram constituídos por osso subcondral compacto, pouco vascularizado, não observando-se reabsorção óssea. A cartilagem de reparação encontrava-se menos diferenciada que a observada nas falhas que tinham as bordas mais

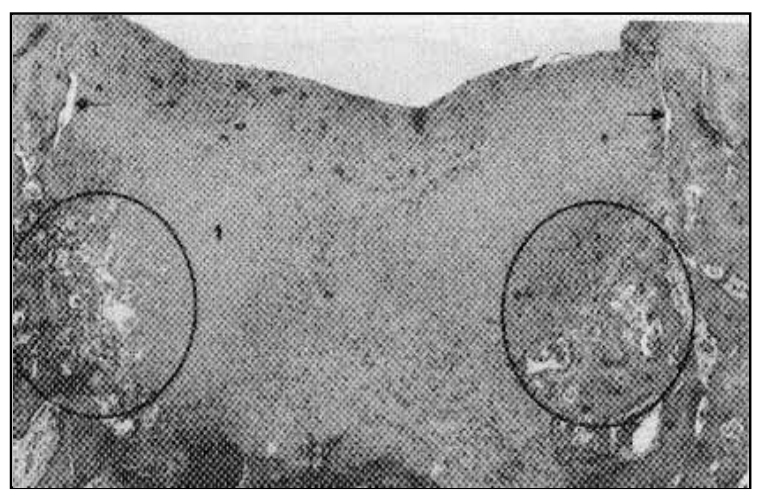

Figura 2 - Aspecto da falha osteocondral após quatro semanas de pós-operatório. Observa-se o preenchimento completo da falha por cartilagem hialina (1) e o início do processo de ossificação endocondral nas laterais (círculo). Pode-se verificar integração do tecido de reparação do fundo da falha ao osso adjacente (setas amarelas). Entretanto, nas laterais, ainda pode ser visualizada a linha de fratura e fendas entre o tecido de reparação e o tecido ósseo (setas pretas). Há boa integração com a cartilagem remanescente na borda da falha (seta vermelha). H \& E. 50X. 
vascularizadas e a matriz era mais acidófila, apresentando algumas áreas com discreta basofilia. Dois animais do grupo apresentaram vacúolos de diferentes tamanhos na cartilagem hialina de reparação.

A cartilagem articular adjacente à falha estava aparentemente normal, embora ainda fossem observadas lacunas vazias e raros clones condroblásticos. Sua integração com o tecido de reparação foi observada somente em um animal, sendo freqüente a formação de fendas entre os dois tecidos nos demais.

Em GIII, um animal apresentou aderência da membrana sinovial à falha osteocondral, observando-se reabsorção das trabéculas ósseas e ausência de reparação da superfície articular. Dois animais apresentaram as falhas preenchidas, predominantemente, por cartilagem hialina, sendo que em um havia organização colunar dos condrócitos na camada radial (Figura 3) e em outro, a falha foi preenchida por fibrocartilagem.

O tecido de reparação estava integrado ao tecido ósseo do fundo da falha, não sendo visualizada a linha de fratura, constatando-se ter havido reabsorção óssea. Porém, nas laterais da falha, a reabsorção não era completa em alguns animais, não ocorrendo integração nestas áreas. Não foi observada invasão da cartilagem de reparação do fundo da falha por vasos sangüíneos em várias áreas, o que limitou o processo de ossificação endocondral, não havendo transformação do tecido de reparação em tecido ósseo. Em um animal, foram observados

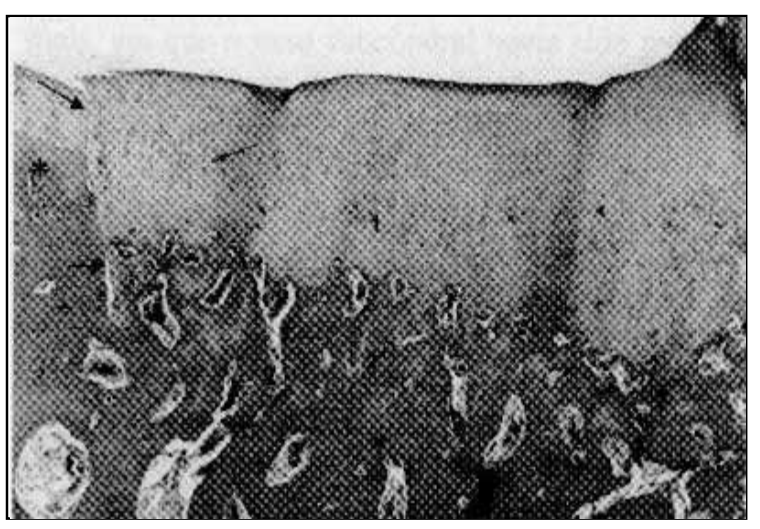

Figura 3 - Com sete semanas de pós-operatório, o tecido de reparação é constituído por cartilagem hialina superficialmente (1), com disposição dos condrócitos em colunas (seta azul). No fundo da falha, pode-se observar osso novo (2), mas o processo de ossificação endocondral ainda não alcançou o nível da junção osteocondral pré-existente (*). São observadas fendas entre o tecido de reparação e o tecido ósseo adjacente (seta curta), havendo também descontinuidade com a cartilagem remanescente, apesar da justaposição tecidual (seta longa). H \& E. 63X. vacúolos de diferentes tamanhos na matriz extracelular da cartilagem hialina de reparação.

A cartilagem articular adjacente à falha apresentou hipocelularidade ainda a sete semanas de pós-operatório. Sua integração com o tecido de reparação foi observada somente em um animal.

\section{DISCUSSÃO}

Os resultados da pesquisa confirmam as observações de que lesões nas superfícies articulares, que incluam toda a cartilagem hialina, penetrando também o osso subcondral, são reparadas a partir de células mesenquimais provenientes da medula óssea, havendo a formação de fibrocartilagem e cartilagem semelhante à hialina, com ou sem a arquitetura típica da cartilagem articular normal. Pesquisadores (MITCHELL \& SHEPARD, 1976; HURTIG et al., 1988; FRENCH et al., 1989; SHAMIS $\boldsymbol{e t}$ al., 1989; KIM $\boldsymbol{e t}$ al., 1991; HANIE $\boldsymbol{e t}$ al., 1992; SHAPIRO et al., 1993) consideraram ainda que a restauração da arquitetura tecidual característica da superfície articular é rara, ocorrendo em número reduzido de falhas osteocondrais, o que foi observado em apenas um animal do GIII.

A osteogênese, responsável pela reposição do osso subcondral excisado, na maioria dos animais, estava restrita à periferia do tecido de reparação a quatro e sete semanas, semelhante ao observado em coelhos por KIM et al. (1991) e SHAPIRO et al. (1993). Pode-se inferir que a ausência de ossificação endocondral até esse período, permanecendo o tecido cartilaginoso até o fundo da falha, pode prejudicar a manutenção da integridade da cartilagem de reparação a longo prazo (SHAPIRO et al., 1993), pois a ausência do "leito" ósseo subcondral impede que a cartilagem de reparação possa receber o impacto de cargas e transmiti-lo ao tecido ósseo subjacente, podendo ocasionar o desenvolvimento de alterações degenerativas (RADIN \& ROSE, 1986).

Nesta pesquisa, os vacúolos, observados somente nos animais em que o osso subcondral não havia sido reconstituído, podem significar sinais precoces de degeneração da cartilagem de reparação relacionados à deficiência do leito vascular. Portanto, pode-se conceber que, apesar da reconhecida importância do osso subcondral na manutenção da integridade da cartilagem articular (RADIN \& ROSE, 1986), sua presença física interferiu desfavoravelmente nas fases iniciais do processo de reparação (FRENCH et al., 1989; KIM et al., 1991). Isso foi observado também naqueles animais, dos três grupos experimentais, em que houve pequena remodelação óssea subcondral. O osso lamelar compacto presente no fundo dessas falhas pode ter representa- 
do uma barreira à chegada de vasos sangüíneos, provenientes da medula óssea, em quantidade suficiente para permitir a remodelação que, quando observada, restringia-se às proximidades dos túneis vasculares que se comunicavam com a falha.

Portanto, os achados histopatológicos desta pesquisa permitiram concordar com FRENCH et al. (1989), quando sugeriram que a curetagem no osso subcondral deve se estender o suficiente para que canais vasculares maiores sejam expostos, possibilitando a ocorrência da resposta cicatricial. Além disso, KIM et al. (1991) observaram pouca evidência de ossificação endocondral ou de formação de osso novo, com até doze semanas de pós-operatório, em falhas nas quais foi realizada somente abrasão do osso subcondral.

$\mathrm{Na}$ maioria dos animais, verificou-se integração do tecido de reparação ao tecido ósseo adjacente. Ressalte-se que essa integração estava presente somente nas áreas onde foi observada reabsorção óssea, reafirmando a importância desta na reparação de falhas osteocondrais. Portanto, a integração esteve relacionada à presença de vasos sanguiíneos e de reabsorção óssea, conforme observaram FRENCH et al. (1989) e HANIE et al. (1992). Quanto ao tipo de tecido exposto, a completa remoção da zona de cartilagem calcificada, de maneira isolada, com exposição do osso subcondral, não implica, necessariamente, a integração do tecido de reparação à falha, diferentemente do que acreditam HURTIG et al. (1988) e SHAMIS et al. (1989).

Os resultados demonstram que, naqueles animais que apresentaram osso subcondral compacto no fundo da falha, o tecido de reparação foi progressivamente integrado, de acordo com a evolução da remodelação óssea, de maneira semelhante ao que foi observado por HURTIG et al. (1988). A sete semanas de pós-operatório, eles apresentaram uma integração tecidual mais extensa do que aquela observada a duas e quatro semanas. E era evidente a relação entre a integração e o momento em que alguns túneis vasculares passaram a se comunicar com a falha, e vasos sangüíneos penetraram o tecido de reparação adjacente.

Fendas entre o tecido de reparação e o tecido ósseo adjacente, com perda de continuidade, foram observadas, algumas vezes, nas laterais da falha e são relatadas por HURTIG $\boldsymbol{e t}$ al. (1988), KIM et al. (1991), HANIE et al. (1992) e SHAPIRO et al. (1993) como uma complicação freqüente. Estas falhas podem acarretar o rompimento do tecido de reparação por forças biomecânicas normais, resultando em exposição do osso subcondral, aos moldes do que acontece nas doenças articulares degenerativas, conforme comprovado por RADIN \& ROSE (1986).
A integração completa entre o tecido de reparação e a cartilagem remanescente na borda da falha foi observada, ocasionalmente, e suas características histológicas foram semelhantes às descritas em lesões osteocondrais de diversos modelos experimentais (RUDD et al., 1987; HURTIG et al., 1988; FRENCH et al., 1989; SHAMIS et al., 1989; SHAPIRO et al., 1993). Ocorreu com freqüência descontinuidade nesse local, apesar de não ter sido realizada incisão oblíqua na cartilagem articular, durante a confecção da falha o que, segundo FRENCH et al. (1989) é prejudicial. Além disso, deve ser relatado que a estreita separação entre esses tecidos pode influenciar a sobrevida da cartilagem de reparação (SHAPIRO et al., 1993) e que o aspecto menos rígido da cartilagem na periferia da lesão pode levar ao seu estiramento e rompimento (RADIN \& ROSE, 1986).

Pode-se afirmar, pelos dados desta pesquisa, que o preenchimento da falha até o nível da superfície articular não implica, necessariamente, a integração entre o tecido de reparação e a cartilagem remanescente, como também observaram SHAPIRO et al. (1993). Além disso, HANIE et al. (1992), ao compararem falhas superficiais com falhas profundas, concluíram que a profundidade da falha também não influenciou essa integração.

\section{CONCLUSÕES}

O processo de reparação da superfície articular se dá por diferenciação de células mesenquimais provenientes de túneis vasculares que comunicam as falhas osteocondrais com espaços medulares; o preenchimento inicial com tecido de granulação sofre diferenciação tecidual em cartilagem hialina, e é importante a remodelação do osso subcondral. Nos procedimentos cirúrgicos em superfícies articulares, é importante que a curetagem remova todo o osso subcondral compacto, expondo o osso esponjoso subcondral e túneis vasculares calibrosos, possibilitando a reparação da lesão osteocondral.

\section{FONTES DE AQUISIÇÃO}

1-Ração Coelhil "R", Socil.

2-Despacilina, Bristol-Myers Squibb.

3-Benzetacil, Wyeth.

4-Neozine, Rhodia, S.A.

5-Zoletil, Virbac S.A.

\section{REFERÊNCIAS BIBLIOGRÁFICAS}

FRENCH, D.A., BARBER, S.M., LEACH, D.H. et al. The effect of exercise on the healing of articular cartilage defects in the equine carpus. Veterinary Surgery, v.18, n.4, p.312-321, 1989. 
GRIMALDI FILHO, G. Manual de técnica histológica. Rio de Janeiro : Instituto Oswaldo Cruz, 1981. 287p.

HANIE, E.A., SULLINS, K.E., POWERS, B.E. et al. Healing of full-thickness cartilage compared with full-thickness cartilage and subchondral bone defects in the equine third carpal bone. Equine Veterinary Journal, v 24, n.5, p.382-386, 1992.

HURTIG, M.B., FRETZ, P.B., DOIGE, C.E. et al.. Effects of lesion size and location on equine articular cartilage repair. Canadian Journal of Veterinary Research, v.52, n.1, p.137146, 1988.

KIM, H.K.W., MORAN, M.E., SALTER, R.B. The potential for regeneration of articular cartilage in defects created by chondral shaving and subchondral abrasion. An experimental investigation in rabbits. The Journal of Bone and Joint Surgery, v.73-A, n.9, p.1301-1315, 1991.

LUNA, L.G. Manual of histologic staining methods of the armed forces institute of pathology. 3.ed. New York : McGraw-Hill Book, 1968. 258p.
MITCHELL, N., SHEPARD, N. The resurfacing of adult rabbit articular cartilage by multiple perforations through the subchondral bone. The Journal of Bone and Joint Surgery, v.58-A, n.2, p.230-233, 1976.

RADIN, E.L., ROSE, R.M. Role of subchondral bone in the initiation and progression of cartilage damage. Clinical Orthopaedics and Related Research, v.213, p.34-40, 1986.

RUDD, R.G., VISCO, D.M., KINCAID, S.A. et al. The effects of beveling the margins of articular cartilage defects in immature dogs. Veterinary Surgery, v.16, n.15, p.378-383, 1987.

SHAMIS, L.D., BRAMLAGE, L.R., GABEL, A.A. et al. Effect of subchondral drilling on repair of partial-thickness cartilage defects of third carpal bones in horses. American Journal of Veterinary Research, v.50, n.2, p.290-295, 1989.

SHAPIRO, F., KOIDE, S., GLIMCHER, M.J. Cell origin and differentiation in the repair of full-thickness defects of articular cartilage. The Journal of Bone and Joint Surgery, v.75A, n.4, p.532-553, 1993.

Ciência Rural, v. 30, n. 3, 2000. 